\title{
CADMIUM, MERCURY AND LEAD IN THE BLOOD OF URBAN WOMEN IN CROATIA, THE CZECH REPUBLIC, POLAND, SLOVAKIA, SLOVENIA, SWEDEN, CHINA, ECUADOR AND MOROCCO
}

NATALIA PAWLAS ${ }^{1}$, ULF STRÖMBERG ${ }^{2}$, BO CARLBERG ${ }^{3}$, MILENA CERNA ${ }^{4}$, FLORENCIA HARARI ${ }^{5}$, RAÚL HARARI ${ }^{5}$, MILENA HORVAT ${ }^{6}$, FRANTISKA HRUBA ${ }^{7}$, KVETOSLAVA KOPPOVA ${ }^{8}$, ANDREA KRSKOVA, MLADEN KRSNIK ${ }^{10}$, YU-FENG LI' ${ }^{11}$, LINA LÖFMARK ${ }^{2}$, THOMAS LUNDH ${ }^{2}$, NILS-GÖRAN LUNDSTRÖM ${ }^{12}$, BADIAÂ LYOUSSI ${ }^{13}$, IWONA MARKIEWICZ-GÓRKA ${ }^{14}$, DARJA MAZEJ ${ }^{6}$, JOSKO OSREDKAR ${ }^{10}$, KRYSTYNA PAWLAS ${ }^{14,15}$, GERDA RENTSCHLER ${ }^{2}$, VERA SPEVACKOVA9, ZDRAVKO SPIRIC ${ }^{16}$, ANNELI SUNDKVIST ${ }^{12}$, JANJA SNOJ TRATNIK ${ }^{6}$, DRAŽENKA VADLA ${ }^{16}$, SOUMIA ZIZI ${ }^{13}$, STAFFAN SKERFVING ${ }^{2}$, and INGVAR A. BERGDAHL ${ }^{12}$

${ }^{1}$ Institute of Occupational Medicine and Environmental Health, Sosnowiec, Poland

Department of Chemical Hazards and Genetic Toxicology

${ }^{2}$ University Hospital, Lund, Sweden

Division of Occupational and Environmental Medicine

${ }^{3}$ Umeå University, Umeå, Sweden

Division of Medicine, Department of Public Health and Clinical Medicine

${ }^{4}$ Charles University in Prague, Third Faculty of Medicine, Prague, Czech Republic

Department of General Hygiene

${ }^{5}$ Institute for the Development of Production and Work Environment, Quito, Ecuador

${ }^{6}$ Institut Jožef Stefan, Ljubljana, Slovenia

Department of Environmental Sciences

${ }^{7}$ Regional Authority of Public Health, Banska Bystrica, Slovakia

Department of Health Informatics and Biostatistics

${ }^{8}$ Regional Authority of Public Health, Banska Bystrica, Slovakia

Department of Environmental Health

${ }^{9}$ National Institute of Public Health, Prague, Czech Republic

Headquarters, Environmental and Population Health Monitoring

Grants were supplied from the European Union (Sixth Framework Programme; PHIME; FOOD-CT-2006-016253) and long series of funding agencies in the participating countries. The paper reflects only the authors' views; the European Union is not liable for any use that may be made of the information. Received: June 25, 2012. Accepted: September 3, 2012.

Corresponding author: N. Pawlas, Institute of Occupational Medicine and Environmental Health, Kościelna 13, 41-200 Sosnowiec, Poland (e-mail: n-pawlas@wp.pl). 
${ }^{10}$ University Medical Centre Ljubljana, Ljubljana, Slovenia

Institute of Clinical Chemistry and Biochemistry

${ }^{11}$ Institute of High Energy Physics, Chinese Academy of Sciences, Beijing, China

Key Laboratory of Nuclear Analytical Techniques

${ }^{12}$ Umeå University, Umeå, Sweden

Department of Public Health and Clinical Medicine, Occupational and Environmental Medicine

${ }^{13}$ University of Fez, Fez Atlas, Morocco

Laboratory of Physiology, Pharmacology and Environmental Health

${ }^{14}$ Wroclaw Medical University, Wrocław, Poland

Department of Hygiene

${ }^{15}$ Institute of Occupational Medicine and Environmental Health, Sosnowiec, Poland

Laboratory of Audiology and Noise

${ }^{16}$ Oikon Ltd, Zagreb, Croatia

\begin{abstract}
Objectives: The aim of the study was to make an international comparison of blood levels of cadmium (B-Cd), lead (B$\mathrm{Pb}$ ) and mercury $(\mathrm{B}-\mathrm{Hg})$ of women in seven European, and three non-European cities, and to identify determinants. Materials and Methods: About 50 women (age: 46-62) from each city were recruited (totally 480) in 2006-2009. Interview and questionnaire data were obtained. Blood samples were analysed in one laboratory to avoid interlaboratory variation. Results: Between the European cities, the B-Pb and B-Cd results vary little (range of geometric means: 13.5-27.0 $\mu \mathrm{g} / \mathrm{l}$ and $0.25-0.65 \mu \mathrm{g} / \mathrm{l}$, respectively); the variation of B-Hg was larger $(0.40-1.38 \mu \mathrm{g} / \mathrm{l})$. Between the non-European cities the results for B-Pb, B-Cd and B-Hg were 19.2-68.0, 0.39-0.99 and 1.01-2.73 $\mu \mathrm{g} / \mathrm{l}$, respectively. Smoking was a statistically significant determinant for $\mathrm{B}-\mathrm{Cd}$, while fish and shellfish intakes contributed to $\mathrm{B}-\mathrm{Hg}$ and $\mathrm{B}-\mathrm{Pb}$, amalgam fillings also contributed to B-Hg. Conclusions: The present results confirm the previous results from children; the exposure to lead and cadmium varies only little between different European cities suggesting that other factors than the living area are more important. The study also confirms the previous findings of higher cadmium and lead levels in some non-European cities. The geographical variation for mercury is significant.
\end{abstract}

Key words:

Cadmium, Mercury, Lead, Blood, Urban Women, European cities, Non-European Cities

\section{INTRODUCTION}

Knowledge about geographical variations in exposures to toxic metals has great importance for risk assessment and management. On the one hand, there is a wealth of information on metal levels in biological media in different countries [1,2], on the other, because the analyses almost always have been made in different laboratories, and the analytical performance varies between these, firm conclusions on geographical differences can seldom be drawn. Strict analytical quality control/quality assurance (QC) QA) measures have been undertaken only in few international studies. For adults, the most recent comparison we know of took place more than 20 years ago [3]. For children, one single recent study, which also included three non-European cities, indicated very small differences between six European cities [4]. In this study, the levels of cadmium (B-Cd), lead (B-Pb) and mercury (B-Hg) in blood samples of women from six European and three non-European cities, and from a mixed urban/rural population in the northern part of Sweden were assessed. All determinations were made in one single laboratory, and under strict QC/QA. Data on children's B-Cd, B-Pb and B-Hg in the same or nearby cities have been reported previously [4]. 


\section{METHODS}

\section{Study area and subjects}

In each country, women from one urban area were recruited. In addition, samples from women participating in a population-based study in northern Sweden, with women from both urban and rural areas, were included, to increase the north-south coverage in that country. In each country we aimed at recruiting 50 women $55-59$ of age. Participation rates are given in Table 1.

Different methods were used for the selection/recruitment of women: Koprivnica, Croatia, recruitment was done by several public lectures and presentations and a call to women in the city. Prague, the Czech Republic, women were recruited among the staff of three governmental organisations (the National Institute of Public Health, the Third Faculty of Medicine and the State Institute for Drug Control). Wroclaw, Poland, women invited for mammography screening were asked, in consecutive order, to participate. Banska Bystrica, Slovakia, a random sample was drawn from the population register of the city. Ljubljana, Slovenia, women were recruited through two workplaces (The Jožef Stefan Institute and University Medical Centre, Ljubljana). Female employers were recruited, as well as wives of male employees, mothers and other family members and their friends. Northern Sweden, blood was sampled among randomly selected women from the counties of Norrbotten and Västerbotten within a populationbased survey [5]. Lund, and southern Sweden, subjects were recruited in a mammography-screening programme in the city and its surroundings. Guiyang, China, primary school teachers' mothers were asked to participate. Camilo Ponce Enríquez, Ecuador, were recruited by public announcement, all women between 55-59 years old living in this city were invited to participate. Fez, Morocco, female patients of a laboratory for medical analyses were recruited.

Local ethics committees in each participating region approved the study and written consent was obtained from each woman.

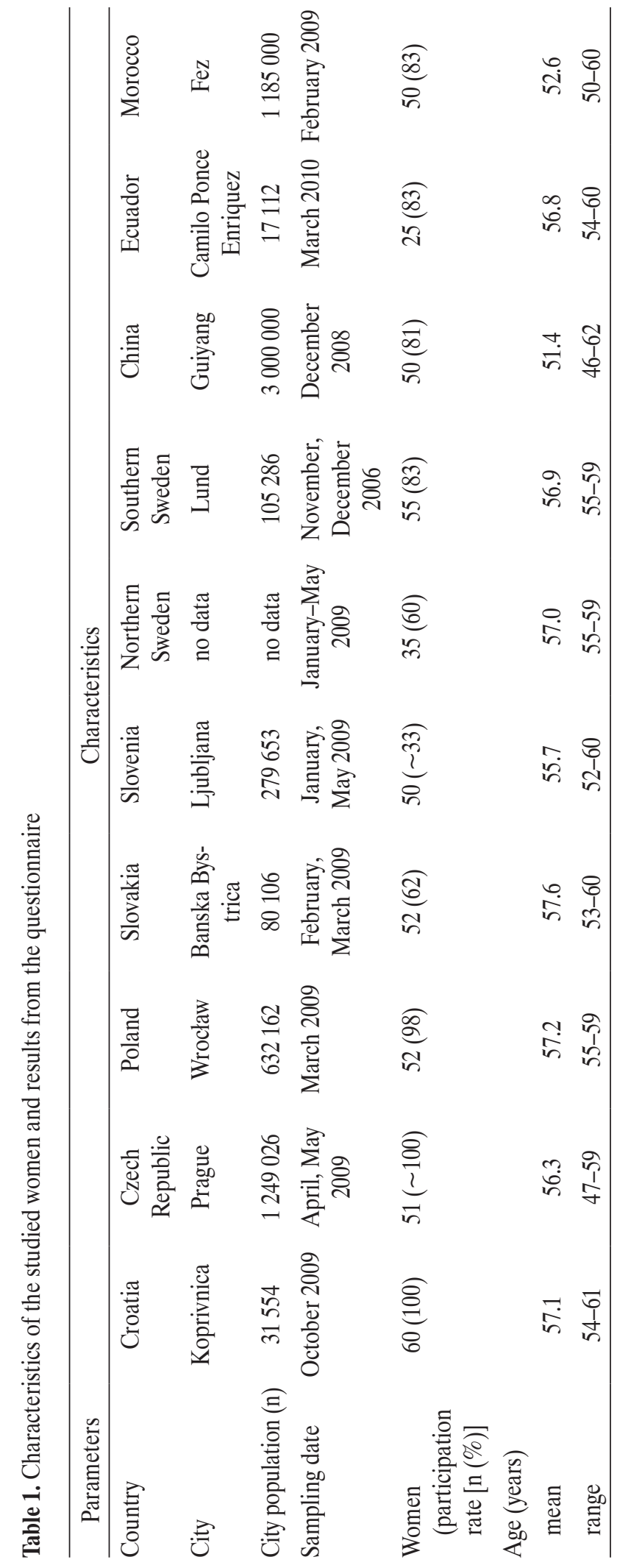




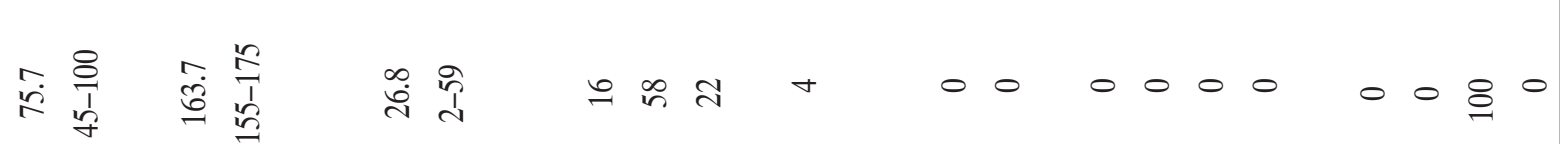

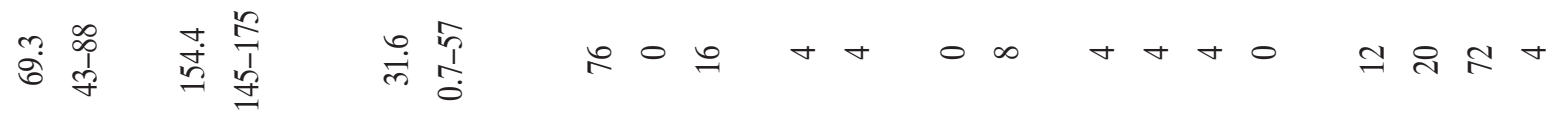

党

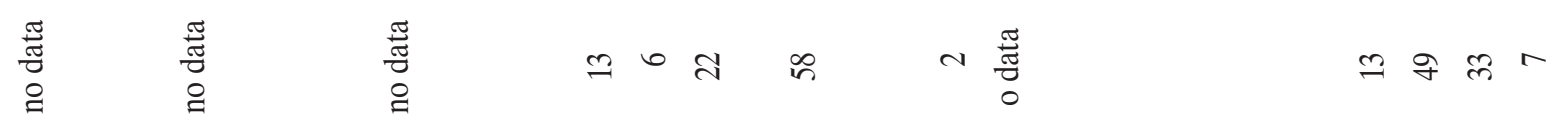

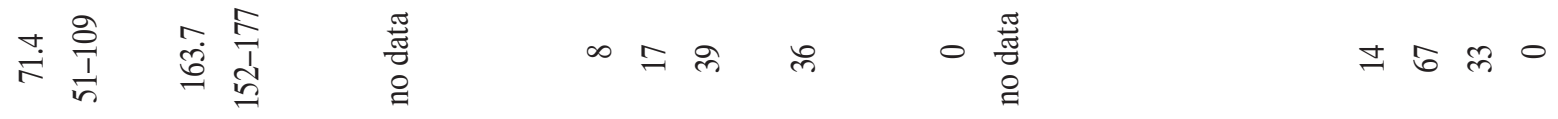

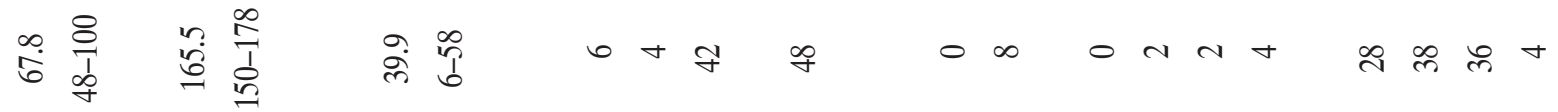

ले

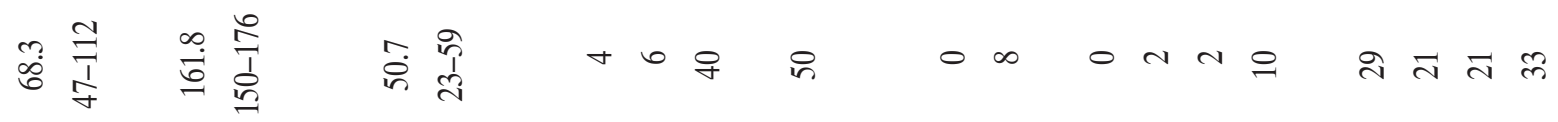

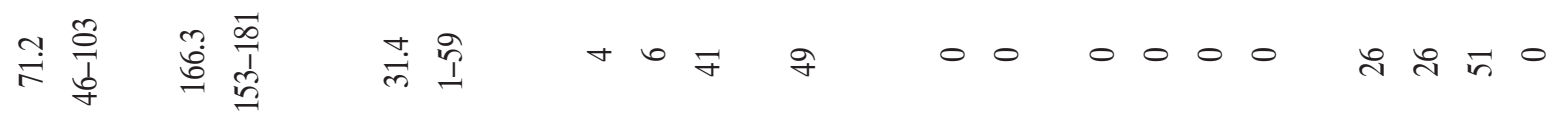

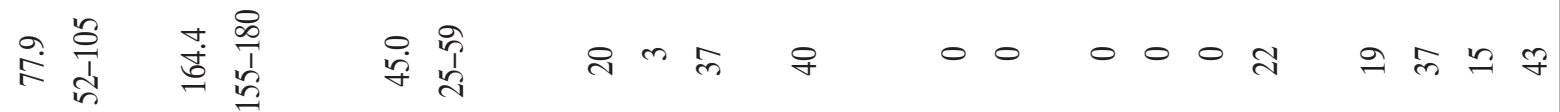

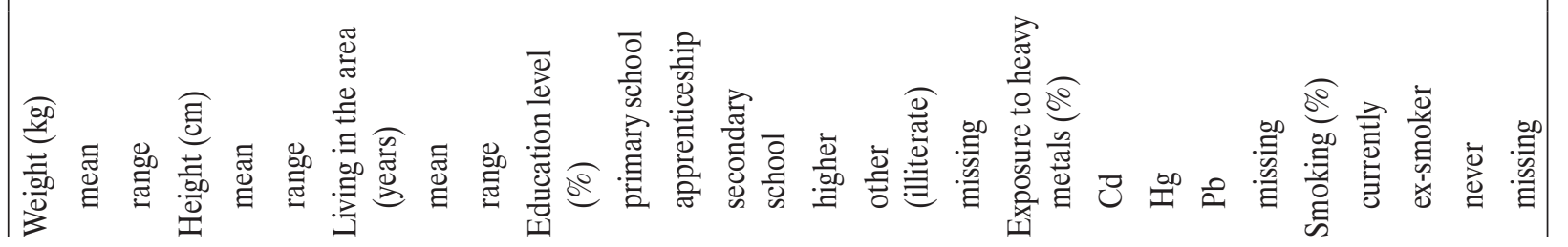




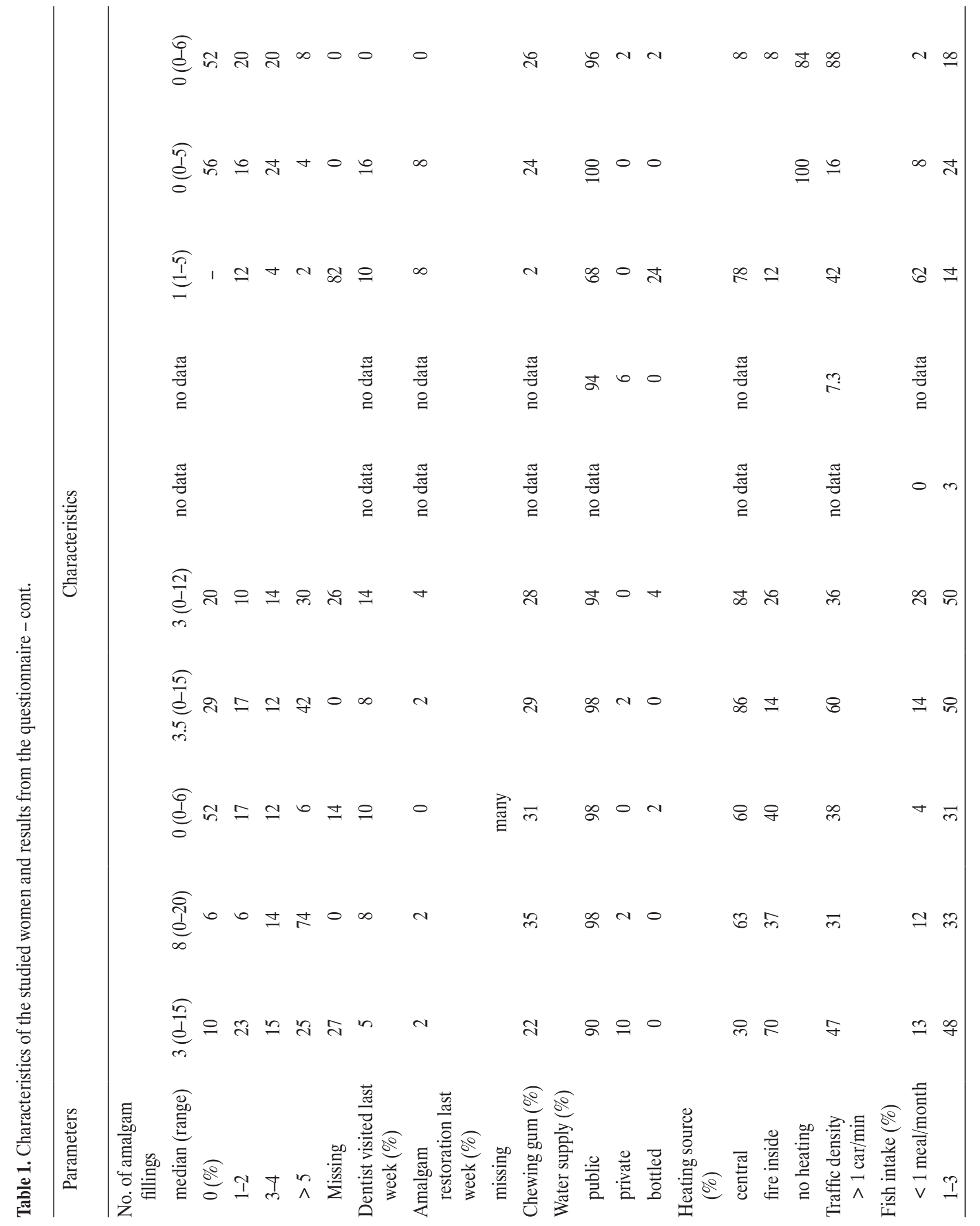




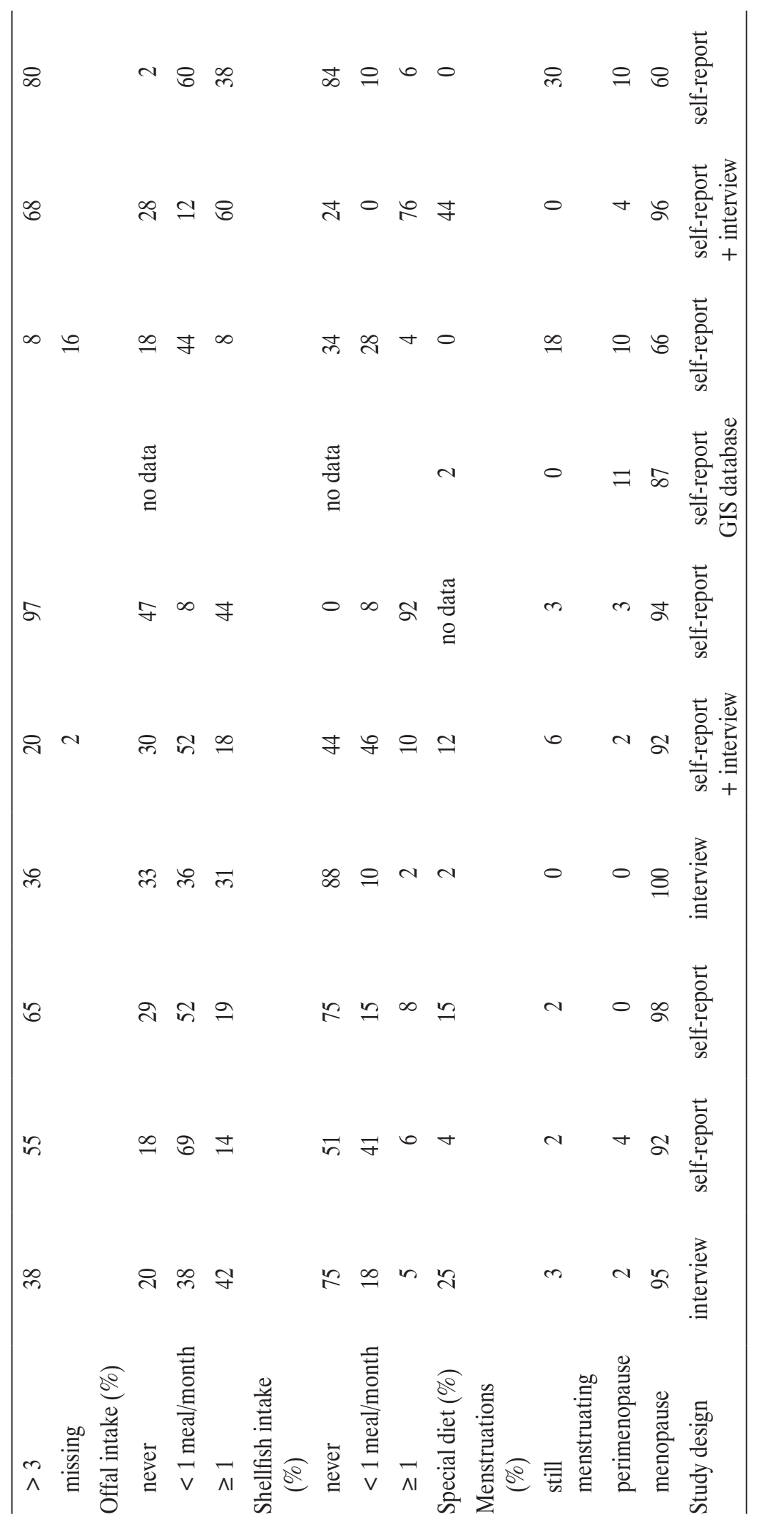

IJOMEH 2013;26(1) 63 


\section{Questionnaire}

A questionnaire for the study was agreed upon by all participating parties and translated into their respective local languages. In most countries, information was obtained through a self-administered questionnaire completed in an interview (Table 1). The two Swedish investigations used somewhat different questionnaires; southern Sweden differed because it carried out a pilot study prior to the others and the northern Sweden study because its sampling was made in connection with an existing monitoring program. Information on individual factors of potential importance for exposure to metals was obtained (see Statistical analyses). Most of the questions had predefined answers (categorical), while some were numerical (number of meals, cigarettes, etc.). Anthropometric data was also collected.

\section{Blood sampling}

After skin cleaning with an ethanol swab, the nurse collected a cubital vein sample of blood into an evacuated tube (Vacuette $4 \mathrm{~mL}$ Lithium Heparin; Greiner-Bio One $\mathrm{GmbH}$, Frickhausen, Germany). Tubes from the same batch were used in all areas. The levels of $\mathrm{Cd}, \mathrm{Pb}$ and $\mathrm{Hg}$ were $<0.03 \mu \mathrm{g} / \mathrm{l}$ at leaching tests of tubes with $4 \mathrm{ml}$ of $2 \%$ nitric acid. Blood samples were stored at $-20^{\circ} \mathrm{C}$ until analyses. Dry ice conditions were used for shipment of samples.

\section{Chemical analyses}

To certify quality and comparability, and to avoid interlaboratory variations, all analyses were made in one laboratory (Division of Occupational and Environmental Medicine, University Hospital, Lund, Sweden) and the sample order was randomized prior to analysis. $\mathrm{B}-\mathrm{Cd}$ and $\mathrm{B}-\mathrm{Pb}$ were determined by inductively coupled plasma-mass spectrometry (ICP-MS; Thermo X7, Thermo Elemental, Winsford, UK) [6]. The detection limits, calculated as three times the standard deviation of the blank, were 0.06 and $0.09 \mu \mathrm{g} / \mathrm{l}$ for $\mathrm{Cd}$ and $\mathrm{Pb}$, respectively. The analytical accuracy was checked against reference material: For Seronorm Trace elements whole blood (Lot. MR4206, 503109, SERO AS, Billingstad, Norway) the results obtained were for $\mathrm{Cd}: 0.70 \pm 0.08 \mu \mathrm{g} / \mathrm{l}$ (mean $\pm \mathrm{SD} ; \mathrm{N}=30$ ) and $6.3 \pm 0.26 \mu \mathrm{g} / \mathrm{l}(\mathrm{N}=27)$ (recommended 0.68-0.80 and 5.6-6.4 $\mu \mathrm{g} / \mathrm{l})$, respectively, and for $\mathrm{Pb}: 29.4 \pm 3.1 \mu \mathrm{g} / \mathrm{l}(\mathrm{N}=27)$ and $408 \pm 13 \mu \mathrm{g} / \mathrm{l}(\mathrm{N}=27)$ (recommended 26.2-29.0 and 372-414 $\mu \mathrm{g} / \mathrm{l}$ ), respectively. For human blood reference samples from Centre de Toxicologie du Quebec, Canada, obtained values for Cd (Lots C0515 and C0912) were $0.79 \pm 0.03$, and $5.32 \pm 0.14 \mu \mathrm{g} / \mathrm{l}(\mathrm{N}=28)$ (recommended $0.79 \pm 0.23$ and $5.33 \pm 0.43 \mu \mathrm{g} / \mathrm{l}$ ), respectively and for $\mathrm{Pb}$ (Lots L0909, and L0807) 24.7 $\pm 1.02 \mu \mathrm{g} / \mathrm{l}$ and $118 \pm 2.9 \mu \mathrm{g} / \mathrm{l}(\mathrm{N}=28) \quad$ (recommended: $22.8 \pm 1.1$ and $110 \pm 9.9 \mu \mathrm{g} / \mathrm{l})$, respectively. B-Hg was determined in acid-digested samples by cold vapour atomic fluorescence spectrophotometry [7]. The detection limit was $0.09 \mu \mathrm{g} / \mathrm{l}$. The analytical accuracy was assessed by Seronorm blood reference samples (Lots MR4206 and 0512627), the results obtained were $2.2 \pm 0.17 \mu \mathrm{g} / \mathrm{l}(\mathrm{N}=106)$ and $15.2 \pm 1.1 \mu \mathrm{g} / \mathrm{l}$ ( $\mathrm{N}=103$ ) (recommended: 2.0-2.4 and 16.1-19.7 $\mu \mathrm{g} /$ ), respectively, and in samples from Centre de Toxicologie du Quebec, Canada (Lot M0408) 2.0 $00.16 \mu \mathrm{g} / \mathrm{l}(\mathrm{N}=28)$ (recommended: $2.2 \pm 0.68 \mu \mathrm{g} / \mathrm{l})$. All analyzed samples were prepared in duplicate and the method inaccuracies (calculated as the coefficients of variation in measurements of duplicate preparations) were $5.4 \%, 5.8 \%$, and $5.8 \%$, for $\mathrm{B}-\mathrm{Cd}$, $\mathrm{B}-\mathrm{Pb}$ and $\mathrm{B}-\mathrm{Hg}$, respectively.

\section{Statistical analyses}

Due to skewed distributions of metal data, geometric means (GMs) were employed for describing average levels. A few B-Hgs ( $\mathrm{N}=14$ ) were negative (lower than the blank), and therefore not possible to log-transform; these were then set to $0.1 \mu \mathrm{g} / \mathrm{l}$ in the statistical computations. We had to exclude women from Northern and Southern Sweden in some of the statistical modeling (because they had not used an identical questionnaire; see above). Effects of the country on bloodmetal concentration were examined by the general linear model procedure. Each potentially influential variable 
(educational level, fish, shellfish and offal intake, amalgam fillings, smoking habits, traffic density close to home, source of water and heating, occupational metal exposure, and chewing gum use) was analyzed in models together with country as a random effect factor. The final model was obtained using backward selection procedure and for each metal included the influential variables that stayed significant $(\mathrm{p}<0.05)$ in the multivariate model. Interactions between country and each significant influential variable were evaluated. The statistical analyses were performed using STATISTICA 9.1 PL software (StatSoft, Inc, 2010).

\section{RESULTS}

\section{Cadmium}

The GM for B-Cd across the European cities ranged from $0.25 \mu \mathrm{g} / \mathrm{l}$ in northern Sweden to $0.65 \mu \mathrm{g} / \mathrm{l}$ in Wrocław, Poland (Table 2, Figure 1). B-Cd in women

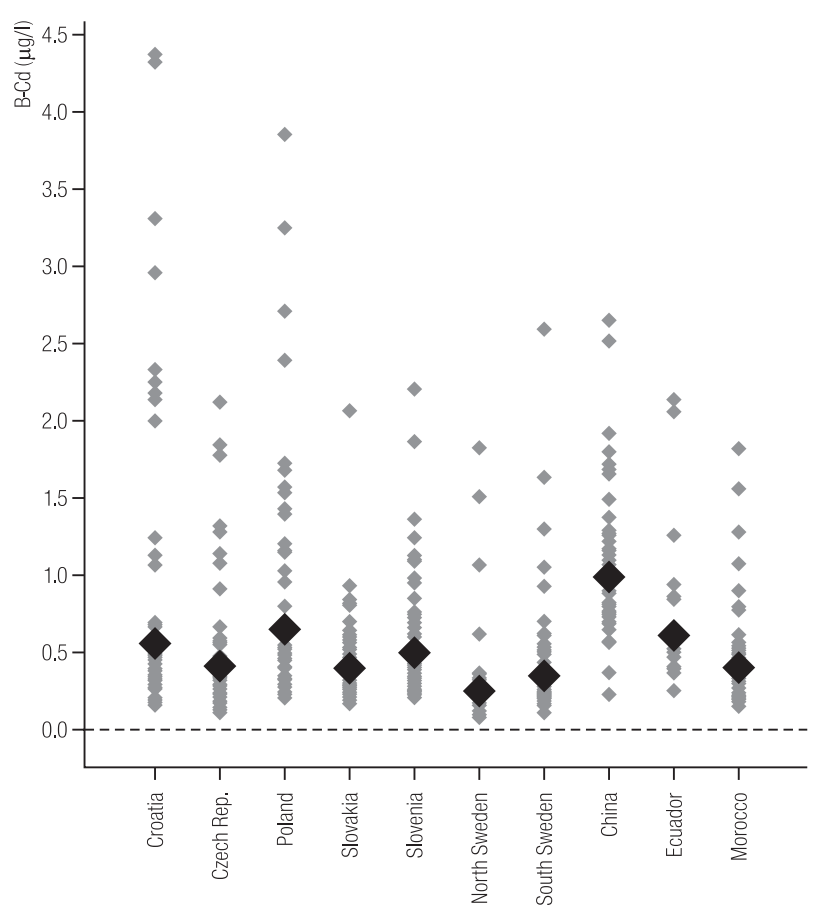

Fig. 1. Concentrations of cadmium (B-Cd) in women from six European and three non-European urban areas

Table 2. Cadmium, lead and mercury in blood in 480 women from different cities

\begin{tabular}{|c|c|c|c|c|c|c|c|c|c|c|c|c|}
\hline \multirow{3}{*}{ City, country } & \multicolumn{6}{|c|}{$\mathrm{B}-\mathrm{Cd}(\mu \mathrm{g} / \mathrm{l})$} & \multirow{2}{*}{\multicolumn{3}{|c|}{$\frac{\mathrm{B}-\mathrm{Pb}(\mu \mathrm{g} / \mathrm{l})}{\text { all }}$}} & \multirow{2}{*}{\multicolumn{3}{|c|}{$\frac{\mathrm{B}-\mathrm{Hg}(\mu \mathrm{g} / \mathrm{l})}{\text { all }}$}} \\
\hline & \multicolumn{3}{|c|}{ all } & \multicolumn{3}{|c|}{ never-smokers } & & & & & & \\
\hline & $\mathrm{n}$ & GM & range & $\mathrm{n}$ & GM & range & $\mathrm{n}$ & GM & range & $\mathrm{n}$ & GM & range \\
\hline Koprivnica, Croatia & 59 & 0.56 & $0.15-4.4$ & 8 & 0.32 & $0.17-0.62$ & 59 & 21.4 & $8.5-48$ & 60 & $0.40(9)^{\mathrm{a}}$ & $<0.1-7.6$ \\
\hline Prague, Czech Republic & 50 & 0.41 & $0.11-2.1$ & 25 & 0.30 & $0.11-0.67$ & 50 & 25.3 & $10.8-92$ & 51 & $0.85(1)$ & $<0.1-8.0$ \\
\hline Wrocław, Poland & 51 & 0.65 & $0.21-3.8$ & 10 & 0.36 & $0.23-0.61$ & 51 & 23.2 & $10.0-69$ & 51 & 0.67 & $0.15-2.9$ \\
\hline Banska Bystrica, Slovakia & 52 & 0.40 & $0.17-2.1$ & 34 & 0.38 & $0.17-0.84$ & 52 & 20.4 & $8.9-74$ & 52 & 0.58 & $0.12-3.3$ \\
\hline Ljubjana, Slovenia & 50 & 0.49 & $0.21-2.2$ & 18 & 0.33 & $0.21-0.76$ & 50 & 26.9 & $12.8-110$ & 50 & $0.68(4)$ & $<0.1-13$ \\
\hline Sweden (north) & 35 & 0.25 & $0.08-1.8$ & 12 & 0.17 & $0.07-0.32$ & 35 & 13.5 & $5.5-61$ & 35 & 1.38 & $0.64-6.4$ \\
\hline Sweden (south) & 55 & 0.35 & $0.11-2.6$ & 18 & 0.27 & $0.15-0.61$ & 55 & 18.5 & 5.9-49 & 54 & 1.37 & $0.21-9.8$ \\
\hline Guiyang, China & 50 & 0.99 & $0.23-2.6$ & 33 & 0.98 & $0.23-2.5$ & 50 & 68.0 & $32.1-230$ & 49 & 2.24 & $0.30-35$ \\
\hline $\begin{array}{l}\text { Camilo Ponce Enriques, } \\
\text { Ecuador }\end{array}$ & 25 & 0.61 & $0.25-2.1$ & 18 & 0.61 & $0.25-2.1$ & 25 & 19.2 & $8.4-42$ & 25 & 2.73 & $0.26-9.8$ \\
\hline Fez, Morocco & 49 & 0.39 & $0.15-1.8$ & 49 & 0.39 & $0.15-1.8$ & 49 & 40.0 & $10.6-130$ & 50 & 1.01 & $0.11-9.1$ \\
\hline
\end{tabular}

$\mathrm{B}-\mathrm{Cd}, \mathrm{B}-\mathrm{Pb}$ and $\mathrm{B}-\mathrm{Pb}$ - cadmium, lead and mercury concentration in the blood of women from six European and three non-European countries. $\mathrm{GM}$ - geometric mean.

${ }^{a}$ Values $<0.1 \mu \mathrm{g} / \mathrm{l}$ were given 0.1 (No. within bracket). 
from Camilo Ponce Enríquez, Ecuador and Fez, Morocco, were within the same range, while Guiyang, China had $0.99 \mu \mathrm{g} / \mathrm{l}$ (all never-smokers). Individual levels within each city varied considerably; the highest concentrations in single samples were found in Koprivnica, Croatia (up to $4.38 \mu \mathrm{g} / \mathrm{l}$ ) and in Wrocław, Poland (up to $3.85 \mu \mathrm{g} / \mathrm{l}$ ). The differences between the European cities were smaller when only women who never smoked were analyzed (from $0.17 \mu \mathrm{g} / \mathrm{l}$ in Northern Sweden to $0.38 \mu \mathrm{g} / \mathrm{l}$ in Banska Bystrica, Slovakia).

\section{Lead}

The GM for $\mathrm{B}-\mathrm{Pb}$ across European cities varied from $13.4 \mu \mathrm{g} / \mathrm{l}$ in northern Sweden to $26.9 \mu \mathrm{g} / \mathrm{l}$ in Ljubljana, Slovenia (Table 2, Figure 2). Individual levels within cities varied substantially. Both Guiyang (China) and Fez (Morocco) had higher B-Pbs - 68.0 and $40.0 \mu \mathrm{g} / \mathrm{l}$, respectively; in Guiyang, the highest individual measurement reached $230 \mu \mathrm{g} / \mathrm{l}$.

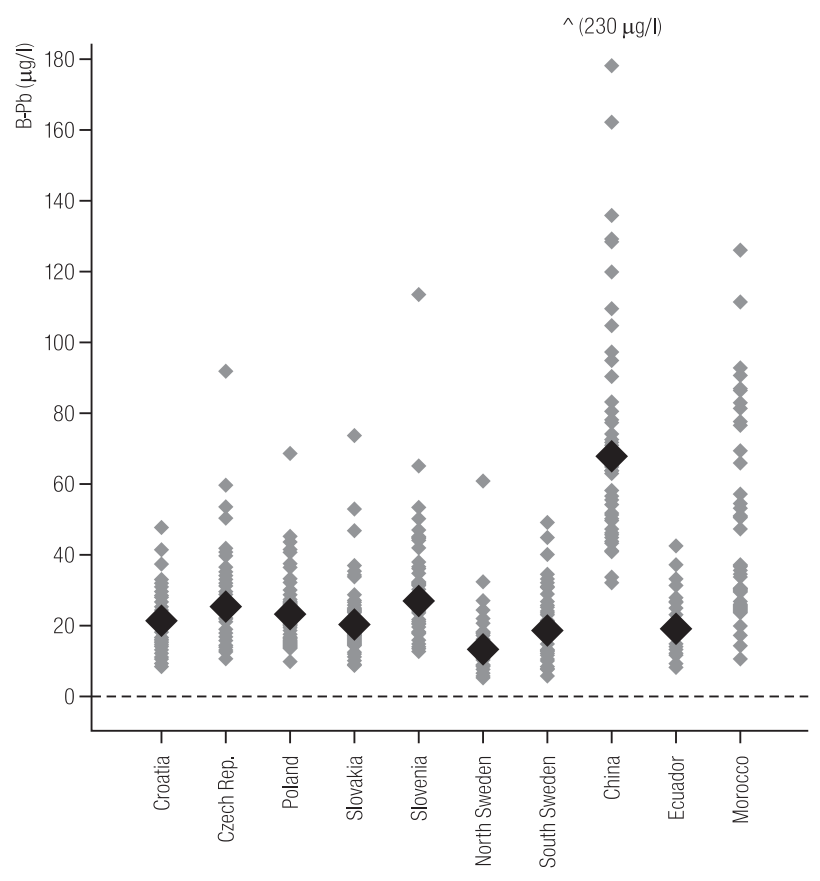

Fig. 2. Concentrations of lead (B-Pb) in women from six European and three non-European urban areas

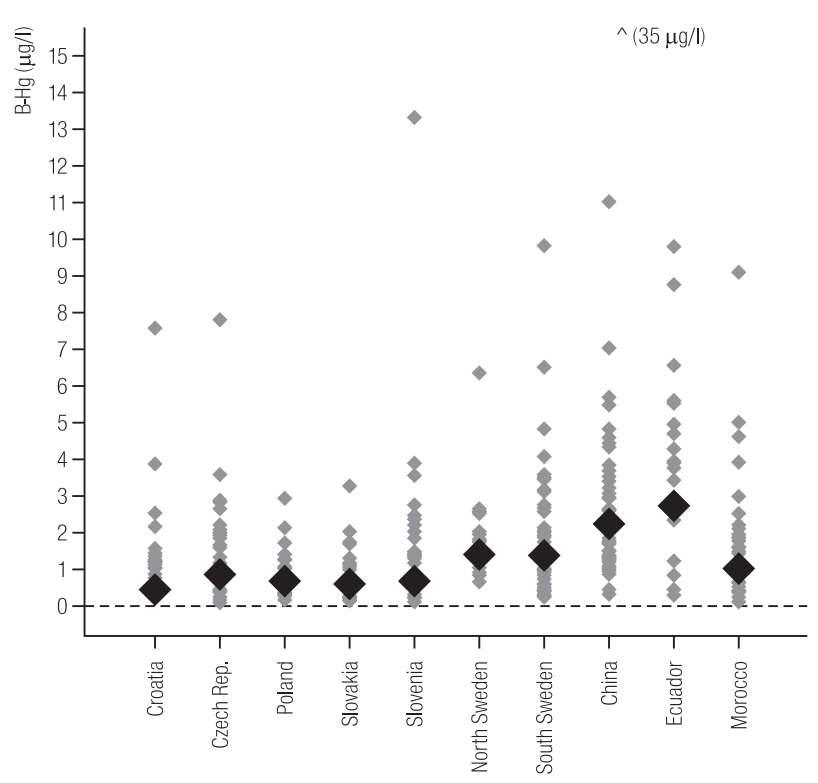

Fig. 3. Concentrations of mercury (B-Hg) in women from six European and three non-European urban areas

\section{Mercury}

The GM for B-Hg across the European cities ranged from $0.40 \mu \mathrm{g} / 1$ in Koprivnica, Croatia to $1.38 \mu \mathrm{g} / \mathrm{l}$ in Northern Sweden (Table 2, Figure 3). Individual levels varied considerably within each city. Women from Guiyang, China, and Camilo Ponce Enriquez, Ecuador, had higher B-Hgs - 2.24 and $2.73 \mu \mathrm{g} / \mathrm{l}$, respectively, while the GM in Fez, Morocco, was in the range of the European cities.

\section{Determinants}

Country/city was an important determining factor; it explained $45 \%$ of the variance for $\mathrm{B}-\mathrm{Pb}$ and $26 \%$ for $\mathrm{B}-\mathrm{Hg}$, but only $17 \%$ for B-Cd (Table 3-5). We found no effect of age on blood levels of metals. However, there was a highly significant effect of smoking on B-Cd; together with city it explained as much as $47 \%$ of the variance, with a highly significant country/smoking interaction (Table 3). Koprivnica, Croatia mainly drove this effect, where smoking explained as much as $66 \%$ of the variance. No significant effect of traffic density was found on B-Cd, B-Pb or B-Hg in all women, including non-smokers. We found marked 
effects of amalgam fillings and fish and shellfish intakes on B-Hg (Table 5). Two models for B-Hg were taken into consideration: The first, including amalgam fillings, fish intake and education level, explained $38 \%$ of the variance, while the second, with shellfish intake instead of educational level (shellfish and education were correlated), explained 37\%. There was significant interaction between amalgam fillings and country, mostly driven by Koprivinica, Croatia, and Banska Bystrica, Slovakia.

\section{DISCUSSION}

The present study of women, which is the first large international study in adults with comparable data for over 20 years, confirms the results of a previous study done on children [4], and shows that the variations of lead and cadmium levels in blood between the six cities in six European countries (the same cities as in a study of children) are very small [4]. For the individual exposure, factors other than nationality are more important. The study also confirms

Table 3. Associations between cadmium concentrations in blood in women and potential determinants

\begin{tabular}{|c|c|c|c|c|c|c|}
\hline $\begin{array}{l}\text { Model including } \\
\text { country only }\end{array}$ & \multirow{2}{*}{ Variable } & \multicolumn{5}{|c|}{ Model with country and other influential variable included } \\
\hline $\mathrm{R}^{2}$ adj & & $\begin{array}{l}\text { multipl. effect } \\
\text { (relative change) }\end{array}$ & $95 \% \mathrm{CI}$ & P for trend & $\mathrm{R}^{2}$ adj & $\begin{array}{c}\text { interaction } \\
\text { variable country }\end{array}$ \\
\hline \multirow[t]{4}{*}{$17 \%$} & current smoking: & & & & & \\
\hline & no & 1.00 & Ref. & $<0.001$ & $47 \%$ & $\begin{array}{c}\mathrm{p}<0.001 \text { (driven } \\
\text { by Croatia)* }\end{array}$ \\
\hline & sometimes & 2.22 & $1.71-2.88$ & & & \\
\hline & regularly & 3.54 & $2.97-4.21$ & & & \\
\hline
\end{tabular}

$\mathrm{R}^{2}$ - explained variance. $95 \% \mathrm{CI}$ - 95\% confidence interval. The difference between countries was statistically significant $(\mathrm{p}<0.001)$.

* Smoking and B-Cd for Croatia: No 1.00; sometimes: 1.68 (1.20-2.36); regularly: 1.93 (1.41-2.66); $\mathrm{p}<0.001 ; \mathrm{R}^{2}=66 \%$.

Table 4. Associations between lead concentrations in blood in women and potential determinants

\begin{tabular}{|c|c|c|c|c|c|c|}
\hline \multirow{2}{*}{$\begin{array}{c}\begin{array}{c}\text { Model including } \\
\text { country only }\end{array} \\
\mathrm{R}^{2} \text { adj }\end{array}$} & \multirow{2}{*}{ Variable } & \multicolumn{5}{|c|}{ Model with country and other influential variable included } \\
\hline & & $\begin{array}{l}\text { multipl. effect } \\
\text { (relative change) }\end{array}$ & $95 \% \mathrm{CI}$ & P for trend & $\mathrm{R}^{2}$ adj & $\begin{array}{c}\text { interaction } \\
\text { variable country }\end{array}$ \\
\hline \multirow[t]{8}{*}{$45 \%$} & fish intake & & & & & \\
\hline & $<1$ meals/month & 1.00 & Ref. & 0.02 & $41 \%$ & $\mathrm{p}=0.5$ \\
\hline & $1-3$ & 0.85 & $0.73-0.98$ & & & \\
\hline & $>3$ & 0.81 & $0.70-0.94$ & & & \\
\hline & shellfish intake: & & & & & \\
\hline & never & 1.00 & Ref. & 0.004 & & $\mathrm{p}=0.5$ \\
\hline & $<1$ meal $/$ month & 1.17 & $1.04-1.31$ & & & \\
\hline & $>1$ & 1.24 & $1.03-1.49$ & & & \\
\hline
\end{tabular}

$\mathrm{R}^{2}$ - explained variance. $95 \mathrm{CI}-95 \%$ confidence interval. The difference between countries was statistically significant $(\mathrm{p}<0.001)$. 
Table 5. Associations between mercury concentrations in blood in women and potential determinants

\begin{tabular}{|c|c|c|c|c|c|c|}
\hline \multirow{2}{*}{$\begin{array}{c}\begin{array}{c}\text { Model including } \\
\text { country only }\end{array} \\
\mathrm{R}^{2} \text { adj }\end{array}$} & \multirow{2}{*}{ Variable } & \multicolumn{5}{|c|}{ Model with country and other influential variable included } \\
\hline & & $\begin{array}{l}\text { multipl. effect } \\
\text { (relative change) }\end{array}$ & $95 \% \mathrm{CI}$ & $P$ for trend & $\mathrm{R}^{2}$ adj & $\begin{array}{c}\text { interaction } \\
\text { variable country }\end{array}$ \\
\hline \multirow[t]{14}{*}{$26 \%$} & education & & & & & \\
\hline & university & 1.00 & Ref. & 0.01 & $38 \%$ & $\mathrm{p}=0.37$ \\
\hline & secondary & 0.71 & $0.57-0.88$ & & & \\
\hline & apprenticeship & 0.84 & $0.61-1.15$ & & & \\
\hline & primary & 0.73 & $0.51-1.04$ & & & \\
\hline & amalgam (No.): & & & & & \\
\hline & 0 & 1.00 & Ref. & 0.001 & & $\mathrm{p}=0.052$ \\
\hline & $1-2$ & 1.24 & $0.95-1.62$ & & & \\
\hline & $3-4$ & 1.11 & $0.85-1.46$ & & & \\
\hline & $>5$ & 1.66 & $1.28-2.16$ & & & \\
\hline & fish intake & & & & & \\
\hline & $<1 \mathrm{meal} /$ month & 1.00 & Ref. & $<0.001$ & & $p=0.09$ \\
\hline & $1-3$ & 1.75 & $1.30-2.35$ & & & \\
\hline & $>3$ & 2.39 & $1.76-3.23$ & & & \\
\hline \multirow[t]{13}{*}{$26 \%$} & amalgam (No.) & & & & & \\
\hline & 0 & 1.00 & Ref. & 0.0026 & $37 \%$ & $\mathrm{p}=0.025^{*}$ \\
\hline & $1-2$ & 1.21 & $0.92-1.57$ & & & \\
\hline & $3-4$ & 1.09 & $0.83-1.43$ & & & \\
\hline & $>5$ & 1.62 & $1.25-2.10$ & & & \\
\hline & fish intake: & & & & & \\
\hline & $<1$ meal $/$ month & 1.00 & Ref. & 0.001 & & $p=0.08$ \\
\hline & $1-3$ & 1.70 & $1.26-2.29$ & & & \\
\hline & $>3$ & 2.27 & $1.67-3.10$ & & & \\
\hline & shellfish intake: & & & & & \\
\hline & never & 1.00 & Ref. & 0.04 & & $p=0.07$ \\
\hline & $<1 \mathrm{meal} / \mathrm{month}$ & 1.18 & 0.94-1.49 & & & \\
\hline & $>1$ & 1.50 & $1.06-2.12$ & & & \\
\hline
\end{tabular}

$\mathrm{R}^{2}$ - explained variance. 95\% CI - 95\% confidence interval. The difference between countries was statistically significant $(\mathrm{p}<0.001)$.

* Amalgam fillings and B-Hg relative change - Croatia: 0 amalgam fillings: 1.00 (ref.); 1-2: 1.10 (0.72-1.69); 3-4: 1.03 (0.63-1.69); > 5: 1.80

(1.18-2.74); $\mathrm{p}=0.02 ; \mathrm{R}^{2}=15 \%$; Slovakia: 0 fillings: 1.00; 1-2: 1.07 (0.76-1.50); 3-4: 0.82 (0.56-1.22); > 5: $1.67(1.29-2.16) ; \mathrm{p}<0.001 ; \mathrm{R}^{2}=27 \%$. 
that higher cadmium and lead levels were present in the three studied non-European cities and the geographical variation for blood mercury is significant.

\section{Design issues}

Earlier comparisons of metal exposure between different countries have almost always been hampered by analyses being made in different laboratories. All blood samples being analysed in one single laboratory, with samples from different countries mixed in the analytical runs, and under careful quality control, to ascertain comparability is a main strength of this study. In addition, samples were analysed locally in most of the participating countries (with larger variations; data not reported here), to facilitate future local follow-ups of time trends. A common questionnaire was used in all countries, except for the two sites in Sweden, where some information is lacking, e.g. on amalgam fillings. Therefore, data from Sweden had to be excluded from some of the multivariate analyses.

Samples women living in the same cities (or nearby) as in the previous study of urban children were chosen [4]. For the recruitment of women, at least two appealing strategies were applied, as suggested previously: One is the sampling of a defined occupational group in different countries (e.g. teachers) [3], another is recruitment of school children mothers [8]. Unfortunately, we had no possibility to use a uniform strategy throughout the countries. The varying recruitment strategies are the most likely explanation of the differences in participation rates. The difference between the different countries' recruitment strategies may have affected the results to an extent: For B-Hg, international differences may stem from confounding factors, e.g., by socioeconomics (B$\mathrm{Hg}$ was associated with education). In contrast, for B-Cd and $\mathrm{B}-\mathrm{Pb}$, differences in recruitment strategies could not have introduced many false differences between the European countries, as the international differences observed were very small.

\section{Geographical variations}

The present results most likely reflect the situation for women in the cities studied. It should be stressed that the relevance is much larger for a small country like Slovenia, than for China, where life conditions vary significantly. A sample size of 50 gives very limited information on the exposure in the studied Chinese city, which has 3 million inhabitants. Nevertheless, cadmium and lead exposures appear to be quite similar to Europe. One could argue that the density of heavy industry, e.g. in Poland, the Czech Republic and Slovakia during the second half of the 20th century, gives reasons to expect elevated exposures. Both the previous study of children [4] and the intake estimates presented by European Food Safety Authority (EFSA) $[9,10]$ indicate small differences within Europe, though there are contaminated areas, e.g. in Poland and Slovakia, with exposures that are of definite health concern.

For mercury, the international variation is considerable and may be explained by differences in amalgam tooth restoration practice, and in consumption and contamination of fish.

When comparing the geometric means of the present study with those of the children from the same cities that were analysed in the same laboratory [4], B-Cd shows a quite similar pattern for non-smoking women and children (Figure 4a, b). Unexpectedly, in the European countries, B-Pbs in children displayed a negative association with those in women (Figure 4c). A partial explanation is most likely the decay of $\mathrm{B}-\mathrm{Pb}$ throughout the years [11,12]. Thus, the levels in women will, to a considerable extent, reflect endogenous exposure, which is a result of previous years' higher intake retained in bone. In non-Europeans, the change in exposure over time may be smaller. For B-Hg, the lack of an association (Figure 4d) with a country is easy to understand, since amalgam fillings and fish intake, the two most important sources of mercury, are more prevalent in women than in children, and at the same time, vary between areas. Northern Sweden was the lowest for both B-Cd and B-Pb, showing a lower exposure in the most peripheral part of 

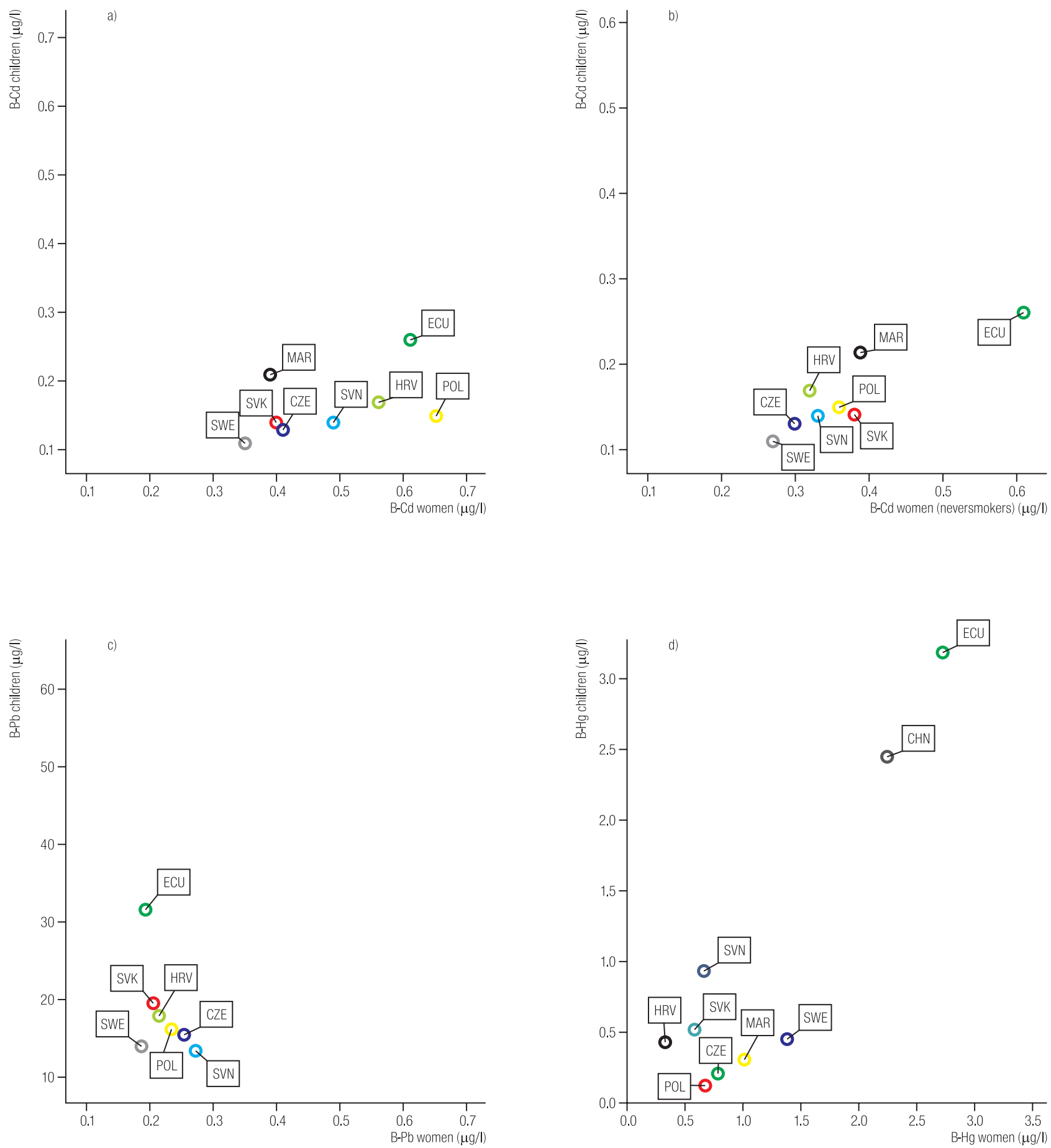

a, b) cadmium (B-Cd), c) lead (B-Pb), and d) mercury (B-Hg) in women (present data) and 433 children (age: 6-14; Hruba et al. [3]) from six European and three non-European cities. For China, only data on B-Hg are available.

CZE - Czech Republic, HRV - Croatia, POL - Poland, SVK - Slovakia, SVN - Slovenia, SWE - Southern Sweden, ECU - Ecuador, CHN - China, MAR - Morocco.

Fig. 4. Concentrations of cadmium, lead and mercury in women and children from European and non-European cities 
Europe. The fact that those women were randomly selected from the whole area, not a city may, to a minor extent, have been a result for the lower exposure. The most likely explanation for the low B-Pb in northern Sweden is the low density of automobiles, with a limited remaining environmental load of petrol lead remnants. The low B-Cd is harder to explain, since the exposure is dominated by the intake of vegetables [9]. Such foods are, maybe with the exception of potatoes, only produced locally. An alternative interpretation might be air pollution from traffic and industries. We have recently found that children's B-Cd is related to traffic intensity near their homes [4]. A theory that inhaled cadmium is of greater importance than generally anticipated postulated. The same association not being observed among the present women weakens the theory.

The concentrations of all three metals were higher in the cities studied in Ecuador, China and Morocco than in European ones. For mercury, the Ecuadorian city is an area where gold mining emits mercury, and mercury is used for amalgamation. In China, coal burning could be a source of mercury emission, especially in the winter [13]. For B-Pb, the use of leaded petrol may still contribute, but both China and Ecuador abandoned lead more than 10 years ago, however, several reports indicate considerable lead exposure in low-income populations where leaded petrol cannot be the explanation [14-16]. B-Cd is higher in Guiyang, China than in the other cities. A possible explanation is extensive consumption of rice, which may contribute to a dietary intake of cadmium being higher than in other cities. Passive smoking, which is prevalent in Chinese women, has sometimes been suggested as a source of cadmium exposure, but scientific data is lacking to support this suggestion.

\section{Health aspects}

The present European levels of metals may be considered low; on the other hand, they confirm that a fraction of the population has exposures to cadmium and lead close to those assumed to be potentially toxic $[9,10]$. For the nonEuropean populations studied here, the margins of safety are even lower. The present mercury exposure is only in a few cases at levels for which toxic effects have been observed [17].

\section{REFERENCES}

1. Skerfving S, Vahter M, Schütz A, Gerhardsson L. Environmental health in the Baltic region - toxic metals. Scand J Work Environ Health 1999;25(Suppl 3):40-64.

2. Smolders R, Alimonti A, Cerna M, Den Hond E, Kristiansen J, Palkovicova L, et al. Availability and comparability of human biomonitoring data across Europe: A case-study on bloodlead levels. Sci Total Environ 2010;408:1437-45.

3. Vahter M, Slorach S. Exposure monitoring of lead and cadmium. An international pilot study within the UNEP/WHO human exposure assessment location (HEAL) project. Technical report. WHO; 1991; Nairobi. p. 82.

4. Hruba F, Stromberg U, Cerna M, Chen C, Harari F, Harari R, et al. Blood cadmium, mercury, and lead in children: An international comparison of cities in six European countries, and China, Ecuador, and Morocco. Environ Int 2012;41:29-34.

5. Stegmayr B, Lundberg V, Asplund K. The events registration and survey procedures in the Northern Sweden MONICA Project. Scand J Public Health 2003;31(Suppl 61):9-17.

6. Barany E, Bergdahl IA, Schütz A, Skerfving S, Oskarsson A. Inductively coupled plasma mass spectrometry for direct multielement analysis of diluted human blood and serum. J Anal Atom Spectrom 1997;12:1005-9.

7. Sandborgh-Englund G, Elinder CG, Langworth S, Schütz A, Ekstrand J. Mercury in biological fluids after amalgam removal. J Dent Res 1998;77:615-24.

8. COPHES (Consortium to Perform Human Biomonitoring on a European Scale) [cited 2012 June 24]. Available from URL: http://www.eu-hbm.info/cophes.

9. European Food Safety Authority. Scientific opinion: cadmium in food. EFSA J 2009;980:1-139. 
10. European Food Safety Authority. Scientific opinion: Lead in food. EFSA J 2010;8(4):1570-717.

11. Strömberg U, Lundh T, Skerfving S. Yearly measurements of blood lead in Swedish children since 1978: The declining trend continues in the petrol-lead-free period 1995-2007. Environ Res 2008;107:332-5.

12. Wennberg M, Lundh T, Bergdahl IA, Hallmans G, Jansson JH, Stegmayr B, et al. Time trends in burdens of cadmium, lead, and mercury in the population of northern Sweden. Environ Res 2006;100:330-8.

13. Feng X, Tang S, Shang L, Yan H, Sommar J, Lindqvist O. Total gaseous mercury in the athmosphere of Guiyang, PR China. Sci Tot Environ 2003;304:61-72.
14. Anticona C, Bergdahl IA, Lundh T, Alegre Y, San Sebastian M. Lead exposure in indigenous communities of the Amazon basin, Peru. Int J Hyg Environ Health 2011;215:59-63.

15. Barbosa FJ, Fillion M, Lemire M, Passos CJ, Rodrigues JL, Philibert A, et al. Elevated blood lead levels in a riverside population in the Brazilian Amazon. Environ Res 2009;109(5):594-9.

16. Bergkvist C, Kippler M, Hamadani JD, Grandér M, Tofail F, Berglund M, et al. Assessment of early-life lead exposure in rural Bangladesh. Environ Res 2010;110(7):718-24.

17. Berlin M, Zalups RK, Fowler BA. Mercury. In: Nordberg GF, Fowler BA, Nordberg M, Friberg LT, editors. Handbook on the toxicology of the metals. 3rd ed. New York: Academic Press, Elsevier; 2007. p. 675-729.

This work is available in Open Access model and licensed under a Creative Commons Attribution-NonCommercial 3.0 Poland License - http://creativecommons.org/ licenses/by-nc/3.0/pl/deed.en. 